\title{
Reduced vs. standard dose native E. coli-asparaginase therapy in childhood acute lymphoblastic leukemia: long-term results of the randomized trial Moscow-Berlin 2002
}

\author{
Alexander Karachunskiy ${ }^{1,2,21}$ (1) - Gesche Tallen ${ }^{3,4,5}$. Julia Roumiantseva ${ }^{1,2} \cdot$ Svetlana Lagoiko $^{1} \cdot$ Almira Chervova $^{1}$. \\ Arend von Stackelberg ${ }^{3}$. Olga Aleinikova ${ }^{6}$. Oleg Bydanov ${ }^{6} \cdot$ Lyudmila Bajdun $^{7} \cdot$ Tatiana Nasedkina $^{1}$. \\ Natalia Korepanova ${ }^{8}$ - Sergei Kuznetsov ${ }^{8}$. Galina Novichkova ${ }^{1,2}$. Marina Goroshkova ${ }^{9}$. Dmitry Litvinov ${ }^{1,2}$. \\ Natalia Myakova ${ }^{1}$. Natalia Ponomareva ${ }^{7}$. Evgeniya Inyushkina ${ }^{10} \cdot$ Konstantin Kondratchik $^{2,11}$. Julia Abugova ${ }^{1}$. \\ Larisa Fechina ${ }^{12}$. Oleg Arakaev ${ }^{12}$. Alexander Karelin ${ }^{1}$. Vladimir Lebedev ${ }^{13}$. Natalia Judina ${ }^{14}$. Gusel Scharapova ${ }^{15}$. \\ Irina Spichak ${ }^{16}$. Anastasia Shamardina ${ }^{17}$. Olga Ryskal ${ }^{18}$. Alexander Shapochnik ${ }^{19}$. Alexander Rumjanzew ${ }^{1,2}$. \\ Joachim Boos ${ }^{20}$. Günter Henze ${ }^{2,3}$. for the ALL-MB study group
}

Received: 14 June 2018 / Accepted: 1 February 2019 / Published online: 6 March 2019

(C) The Author(s) 2019

\begin{abstract}
Purpose Favorable outcomes were achieved for children with acute lymphoblastic leukemia (ALL) with the first Russian multicenter trial Moscow-Berlin (ALL-MB) 91. One major component of this regimen included a total of 18 doses of weekly intramuscular (IM) native Escherichia coli-derived asparaginase (E. coli-ASP) at $10000 \mathrm{U} / \mathrm{m}^{2}$ during three consolidation courses. ASP was initially available from Latvia, but had to be purchased from abroad at substantial costs after the collapse of Soviet Union. Therefore, the subsequent trial ALL-MB 2002 aimed at limiting costs to a reasonable extent and also at reducing toxicity by lowering the dose for standard risk ( $\mathrm{SR}-$ ) patients to $5000 \mathrm{U} / \mathrm{m}^{2}$ without jeopardizing efficacy.

Methods Between April 2002 and November 2006, 774 SR patients were registered in 34 centers across Russia and Belarus, 688 of whom were randomized. In arm ASP-5000 $(n=334)$, patients received $5000 \mathrm{U} / \mathrm{m}^{2}$ and in arm ASP-10000 $(n=354)$ $10000 \mathrm{U} / \mathrm{m}^{2} \mathrm{IM}$.

Results Probabilities of disease-free survival, overall survival and cumulative incidence of relapse at 10 years were comparable: $79 \pm 2 \%, 86 \pm 2 \%$ and $17.4 \pm 2.1 \%$ (ASP-5000) vs. $75 \pm 2 \%$ and $82 \pm 2 \%$, and $17.9 \pm 2.0 \%$ (ASP-10000), while death in complete remission was significantly lower in arm ASP-5000 (2.7\% vs. 6.5\%; $p=0.029)$.

Conclusion Our findings suggest that weekly $5000 \mathrm{U} / \mathrm{m}^{2}$ E. coli-ASP IM during consolidation therapy are equally effective, more cost-efficient and less toxic than $10000 \mathrm{U} / \mathrm{m}^{2}$ for SR patients with childhood ALL.
\end{abstract}

Keywords Acute lymphoblastic leukemia $\cdot$ Children · Native Escherichia coli-derived asparaginase $\cdot$ Multicenter trial

Alexander Karachunskiy and Gesche Tallen contributed equally to this work.

Electronic supplementary material The online version of this article (https://doi.org/10.1007/s00432-019-02854-x) contains supplementary material, which is available to authorized users.

Alexander Karachunskiy

aikarat@mail.ru

Extended author information available on the last page of the article

\section{Introduction}

Since Oettgen et al. have first described the antileukemic effects of L-asparaginase (ASP) in 1967, the bacterial enzyme has become a mainstay in both remission induction and post-induction consolidation (Oettgen et al. 1967). Its use in combination with multiagent chemotherapy resulted in a significant increase of long-term event-free survival (EFS) for children and adolescents with acute lymphoblastic leukemia (ALL) over the last decades.

Dependent on various factors, such as origin (Escherichia coli-derived ASP, E. coli-ASP or Erwinia chrysanthemiderived ASP), preparation (native E. coli- or Erwinia-ASP, 
pegylated E. coli-ASP [PEG-ASP] or recombinant ASP), dosing, and route of administration (intramuscular, IM vs. intravenous, IV), ASP is regularly associated with adverse effects. Life-threatening side effects may be thrombosis, necrotizing pancreatitis, and hypersensitivity reactions (HSR) due to antibodies directed against ASP, the latter especially after prolonged and IV administration (Schmiegelow et al. 2016; Ko et al. 2015). HSR represent by far the most frequent cause of treatment discontinuation or delays and product shifts, thereby jeopardizing efficacy of therapy and resulting in additional treatment costs (Ko et al. 2015). Also, ASP-related myelosuppression requiring dose reductions of other antineoplastic agents during consolidation has been reported (Oehlers et al. 1969; Kolarz and Pietschmann 1971; Johnston et al. 1974; Merryman et al. 2012).

Because of its lower immunogenicity and longer half-life, similar antileukemic efficacy and levels of asparagine serum depletion when compared to the native preparations, multiple groups recommend the PEG formulation for frontline treatment (Rizzari et al. 2006, 2013; Rizzari 2015; Pieters et al. 2011; Tong et al. 2014; Place et al. 2015).

Therapy aims at achieving prolonged or even complete depletion of serum asparagine. Nevertheless, despite the long-term use of ASP, optimal route of administration and dosing as well as most appropriate second-line treatment remain matters of debate (Rizzari et al. 2013; Place et al. 2015; Alrazzak et al. 2016; Beaupin et al. 2017). According to Western European protocols for childhood ALL, ASP is mostly given IV, whereas the IM route is preferred in most US protocols. The pharmacology varies considerably between these modalities, in particular regarding the halflife of the enzyme, which is longer after IM administration (Ho et al. 1981; Narta et al. 2007; Boos et al. 1996). ASP has been given IM at variable single doses up to $30,000 \mathrm{U} /$ $\mathrm{m}^{2}$. Compared to other drugs used for treatment of childhood ALL, ASP is relatively costly. Expenditures differ between preparations (PEG-ASP is more expensive than native ASP), origin (Erwinia-ASP is more expensive than E. coli-ASP), and protocol design (total cumulative dose administered). Cost-efficient treatments have come to focus not only in countries with low income.

In 1986, Clavell et al. published favorable results with four-agent induction and intensive ASP (Clavell et al. 1986). In the first Russian multicenter protocol Moscow-Berlin (ALL-MB) 91, we chose a less intensive regimen and used $10,000 \mathrm{U} / \mathrm{m}^{2}$ E.-coli-ASP IM weekly during consolidation. The aim was to achieve high EFS rates with side effects that are manageable in local health care facilities (Karachunskiy et al. 2008). According to the ALL-MB91 risk definition, standard risk (SR-) patients comprised about $70 \%$ of the total cohort and achieved high EFS rates (over 70\%). For the subsequent trial, MB 2002, encouraged by the positive result of MB 91 and also in the pursuit of an economic therapy, we investigated whether a lower dose of ASP for SR patients would reduce costs and possibly also toxicity without jeopardizing efficacy of the treatment. Hence, SR patients in remission were randomized to receive ASP either at a weekly standard dose of $10,000 \mathrm{U} / \mathrm{m}^{2}$ or a reduced dose of $5000 \mathrm{U} / \mathrm{m}^{2} \mathrm{IM}$ during consolidation.

\section{Patients and methods}

\section{Study design}

The study ALL-MB 2002 was designed as a prospective, multicenter randomized trial addressing several questions. The treatment overview is shown in Supplementary Fig. 1. After diagnosis, all patients were randomized to receive either dexamethasone (DEXA) or methylprednisolone (MePRED) during remission induction (Karachunskiy et al. 2015). For patients achieving complete remission (CR), two additional randomizations were performed. Eligible for the ASP-randomization were only SR patients who had to meet all of the following criteria: White blood cell count (WBC) $<50,000 / \mathrm{mm}^{3}$, no T-cell immunology, no central nervous system (CNS) leukemia, age at diagnosis $>1$ year, no $t(4 ; 11)$ or $t(9 ; 22)$, and being in CR on day 36 . According to this definition, the SR group comprised $70 \%$ of the total cohort enrolled in the trial. Following induction chemotherapy, all eligible patients, irrespective of the glucocorticoid administered during induction, were randomly assigned to one of two ASP-regimens during three consolidation phases. Patients received a total of 18 doses of $E$. coli-ASP (Asparaginase medac $\left.{ }^{\mathrm{TM}}\right)$ at $10,000 \mathrm{U} / \mathrm{m}^{2}$ (ASP-10000) or $5000 \mathrm{U} /$ $\mathrm{m}^{2}$ (ASP-5000) IM at weekly intervals.

\section{Statistical analyses}

The study was planned as a non-inferiority study. To confirm that the outcome in arm ASP-5000 was not inferior to that in ASP-10000 (power 80\%, $p<0.05$ ), the calculated number of patients required for randomization was 304 per group assuming a non-inferiority limit of $<10 \%$. Estimates of disease-free survival (DFS) and overall survival (OS) probability ( \pm standard error) were calculated from the date of randomization to the date of an event (DFS: relapse, death, secondary malignancy; OS: death of any cause). Data were visualized using the Kaplan-Meier method and compared by log-rank test. Cumulative incidences (CI) were estimated according to Kalbfleisch and Prentice. Plots and statistical comparisons were performed using Gray's test. Follow-up monitoring was based on semi-annual questionnaires.

Toxicity comparison was based on regular reports on side effects provided by the treatment centers participating in the trial. Analyzed side effects included those requiring either 
a change to another ASP preparation or discontinuation of ASP therapy, respectively, such as severe HSR (anaphylaxis), pancreatitis and thrombosis.

Frequencies and distributions were compared using the $\chi^{2}$ or Fisher's exact test. For calculations, Graphpad Prism version 3.0 (Graphpad Software Inc., San Diego, CA, USA), Statistica version 7.0 (Statsoft Inc., Tulsa, OK, USA) and R version 2.4.0 were used on a database closed May 1, 2016.

\section{Patients}

Between April 18, 2002, and October 1, 2006, 774 unselected, consecutive SR patients, aged 1-19 years with newly diagnosed precursor B- or T-cell ALL were registered in 34 centers across Russia and Belarus after approval by local ethics committees. Written informed consents for trial-participation and randomization were obtained from parents and patients, if applicable, or their legal guardians according to the Declaration of Helsinki. The consort diagram is shown in Fig. 1a. Participation was refused by 32 patients, seven patients preferred not to be treated in any of the participating centers. Eight patients were excluded due to severe concomitant diseases, and for 12 patients therapy was changed without medical reason, leaving 715 patients eligible for study. Twenty-one patients died during induction, and six patients refused the randomization. Thus, a total of 688 patients were randomized to either arm ASP-5000 or ASP-10000. All other treatment elements were identical; the overview is shown in Fig. $1 b$.

\section{Definitions}

Diagnostic criteria and procedures have been described elsewhere (Karachunskiy et al. 2008, 2015). CNS involvement was defined as $>5$ nucleated cells $/ \mu$ cerebrospinal fluid (CSF) with clearly detectable leukemic blasts in the absence of blood contamination, or as leukemic CNS-infiltration disclosed by imaging (CT or MRI), respectively. TEL/AML1, BCR/ABL-, and MLL/AF4 fusion transcripts were identified by cytogenetics or molecular genetics. SR criteria have been described above. CR was diagnosed in the absence of any evidence of leukemia (i.e., normal CSF and a regenerating bone marrow (BM) with $<5 \%$ leukemia cells). Relapse was defined as reappearance of leukemia at any site.

\section{Treatment}

At diagnosis, all patients were randomized to receive either DEXA at a dose of $6 \mathrm{mg} / \mathrm{m}^{2} /$ day orally (PO) or MePRED $60 \mathrm{mg} / \mathrm{m}^{2} /$ day (PO). Treatment was given as shown in Table 1. After remission was achieved, SR patients were additionally randomized to either arm ASP-5000 or ASP10000 (18 doses of asparaginase $5000 \mathrm{U} / \mathrm{m}^{2}$ or $10,000 \mathrm{U} /$ $\mathrm{m}^{2}$ given weekly IM; exclusively Asparaginase medac ${ }^{\mathrm{TM}}$ was used). In the case of anaphylaxis, E. coli-ASP was discontinued. Patients received three consolidation courses, differing only concerning the asparaginase dose (Fig. 1b; Table 1). After completion of consolidation, maintenance therapy was given for 1.5 years (Table 1 ).

\section{Results}

Of the 688 patients eligible for randomization, 334 were randomized to arm ASP-5000 and 354 to arm ASP-10000 (Fig. 1; Table 2). No significant differences were found between arms regarding gender, age, initial WBC, splenomegaly or genetic aberrations. Patients were also equally distributed with respect to glucocorticoid randomizations and did not differ in early response to therapy (Table 2). Median follow-up of patients remaining in CR was 10.61 years (interquartile range (IQR) 10.08-11.13).

No difference was found between randomization arms with respect to total relapse rates $(17.8 \%$ and $17.4 \%$, respectively; $p=0.96$ ), relapse sites, and incidences of secondary malignancies (Table 3). Also, probabilities of disease-free survival (DFS) at 10 years were not significantly different (arm ASP-5000: $79 \pm 2 \%$, arm ASP-10000: $75 \pm 2 \%$; $p_{\text {log-rank }}=0.155$; Fig. $2 \mathrm{a}$ ). The probability of overall survival (pOS) was slightly superior for patients of arm ASP5000 compared to arm ASP- $10000(86 \pm 2 \%$ and $82 \pm 2 \%$, respectively; $p_{\text {log-rank }}=0.07$; Fig. $2 \mathrm{~b}$ ). The cumulative incidence (CI) of relapse was similar in both arms (Fig. 2c). An advantage of the higher ASP dose was not found in any of the groups. In contrast, DFS was significantly superior in boys, and OS higher in boys and young children (aged $\geq 1-<5$ years) in arm ASP-5000. DFS was independent of the glucocorticoid used during induction (DEXA vs. MePRED) (Table 4; Fig. 2d, e). In contrast, CI of treatmentrelated mortality (TRM) was significantly higher in boys and young children (aged $\geq 1-<5$ years) as well as older children (aged $\geq 10$ years) in arm ASP-10000 (Supplementary Table 1). Death in CR was mainly caused by infections (with comparable incidence in neutropenic and non-neutropenic patients) and occurred significantly less frequently in arm ASP-5000 $(n=9,2.7 \%)$ than arm ASP-10000 $(n=23,6.5 \%)$ $(p=0.029)$ (Table 5). Infections were diagnosed based on clinical findings. Most patients had been suffering from severe, rapidly progressing bacterial and/or fungal infections. Pneumonia was seen in about $50 \%$ of patients; two children in arm ASP-10000 died from fulminant reactivation of hepatitis B. Differences in timepoint of deaths are shown in Table 5. In arm ASP-10000, more than $60 \%$ of treatmentrelated deaths (TRD) were seen late (in consolidation III and maintenance therapy), whereas about $80 \%$ of TRD in arm ASP-5000 occurred early (during consolidation I and II). 


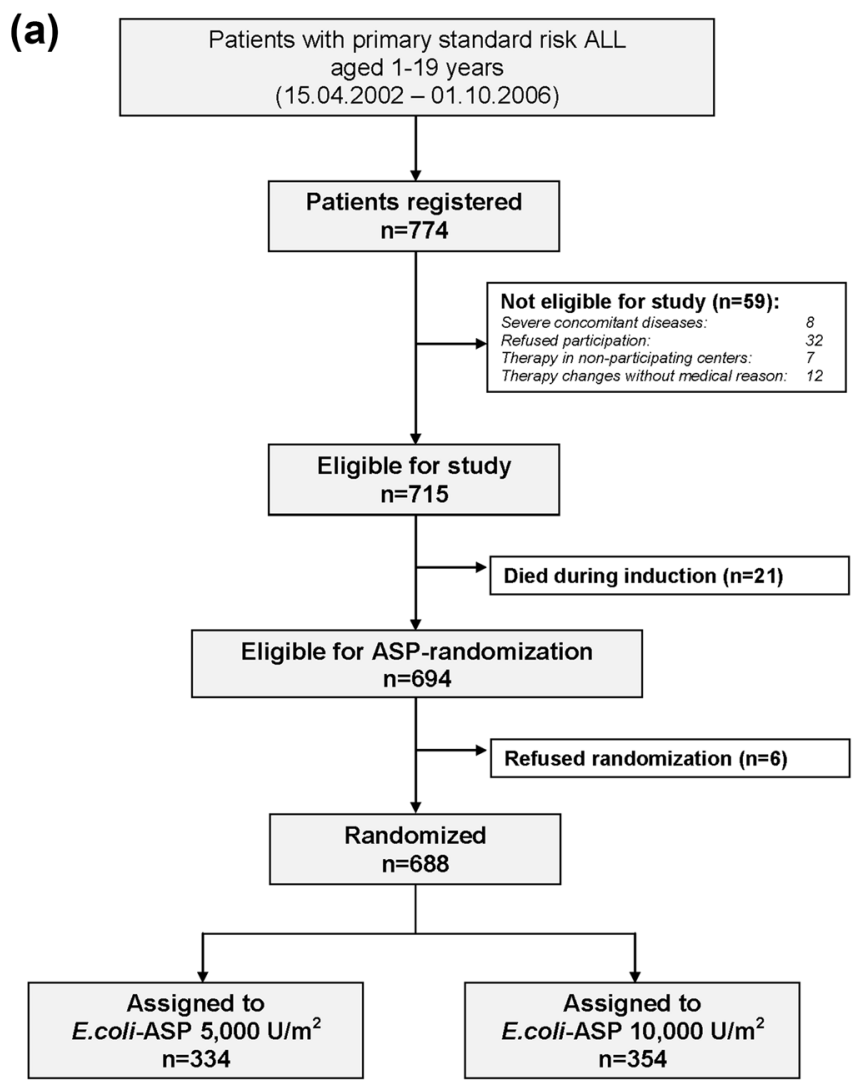

(b)

RANDOMIZATION FOR ASPARAGINASE (ASP) THERAPY IN STANDARD RISK GROUP IN TRIAL ALL-MB 2002

Randomization arm Consolidation1 Consolidation2 Consolidation 3 "ASP-5000"

VCR $1.5 \mathrm{mg} / \mathrm{m}^{2}$

DEXA $6 \mathrm{mg} / \mathrm{m}^{2}$

$\mathrm{MT} \times 30 \mathrm{mg} / \mathrm{m}^{2}$

6-MP $50 \mathrm{mg} / \mathrm{m}^{2}$

TIT

COLI-ASP $5000 \mathrm{U} / \mathrm{m}^{2}$

R2

Randomization arm«ASP -10000 "

VCR $1.5 \mathrm{mg} / \mathrm{m}^{2}$

DEXA $6 \mathrm{mg} / \mathrm{m}^{2}$

$\mathrm{MT} \times 30 \mathrm{mg} / \mathrm{m}^{2}$

6-MP $50 \mathrm{mg} / \mathrm{m}^{2}$

TIT

COLI-ASP $10,000 \mathrm{U} / \mathrm{m}^{2}$ Week
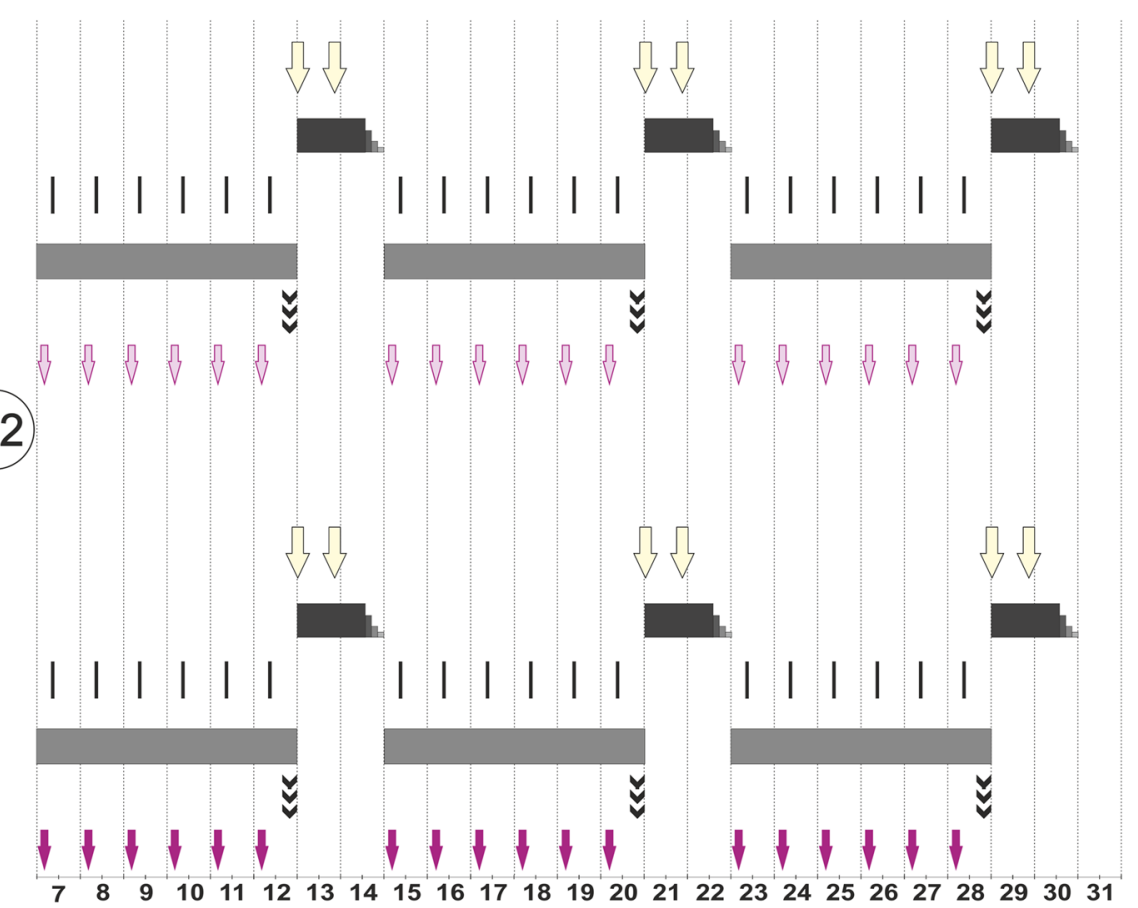
४Fig. 1 a Consort diagram showing recruitment, eligibility, and randomization of standard risk group patients for treatment with $5000 \mathrm{vs.}$ $10,000 \mathrm{U} / \mathrm{m}^{2}$ of $E$. coli-asparaginase (E. coli-ASP) given intramuscularly during consolidation therapy in trial ALL-Moscow-Berlin 2002 (for details, see main text). b Treatment overview: randomization arms ASP-5000 and ASP-10000 in trial ALL-MB 2002
The incidences of pancreatitis and thrombosis were comparable between randomization arms.

Severe HSR occurred significantly more frequently in arm ASP-10000 than ASP-5000 (4.5\% vs. 1.8\%; $p=0.07$ ). In 7 patients of arm ASP-5000 and in more than twice as

Table 1 Treatment protocol of the ALL-MB 2002 trial for standard risk patients

\begin{tabular}{|c|c|c|}
\hline Phase & Dose and route & Days \\
\hline \multicolumn{3}{|l|}{ Induction } \\
\hline Dexamethasone $^{\mathrm{a}}$ & $6 \mathrm{mg} / \mathrm{m}^{2} \mathrm{PO}$ & $1-28$ \\
\hline Methylprednisolone $^{\mathrm{a}}$ & $60 \mathrm{mg} / \mathrm{m}^{2} \mathrm{PO}$ & $1-28$ \\
\hline Vincristine & $1.5 \mathrm{mg} / \mathrm{m}^{2} \mathrm{IV}$ & $8,15,22,29,36$ \\
\hline Daunorubicin & $45 \mathrm{mg} / \mathrm{m}^{2} \mathrm{IV}$ & $8(22)^{b}$ \\
\hline \multicolumn{3}{|l|}{ Consolidation I } \\
\hline 6-Mercaptopurine & $50 \mathrm{mg} / \mathrm{m}^{2} \mathrm{PO}$ & $43-84$ \\
\hline Methotrexate & $30 \mathrm{mg} / \mathrm{m}^{2} \mathrm{IM}$ & $43,50,57,64,71,78$ \\
\hline \multirow[t]{2}{*}{ E. coli-asparaginase ${ }^{\mathrm{c}}$} & $10,000 \mathrm{U} / \mathrm{m}^{2} \mathrm{IM}$ & $44,51,58,65,72,79$ \\
\hline & $5000 \mathrm{U} / \mathrm{m}^{2} \mathrm{IM}$ & $44,51,58,65,72,79$ \\
\hline Dexamethasone & $6 \mathrm{mg} / \mathrm{m}^{2} \mathrm{PO}$ & $85-95$ \\
\hline Vincristine & $1.5 \mathrm{mg} / \mathrm{m}^{2} \mathrm{IV}$ & 85,92 \\
\hline \multicolumn{3}{|l|}{ Consolidation II } \\
\hline 6-Mercaptopurine & $50 \mathrm{mg} / \mathrm{m}^{2} \mathrm{PO}$ & $99-140$ \\
\hline Methotrexate & $30 \mathrm{mg} / \mathrm{m}^{2} \mathrm{IM}$ & $99,106,113,120,127,134$ \\
\hline \multirow[t]{2}{*}{ E. coli-asparaginase ${ }^{\mathrm{c}}$} & $10,000 \mathrm{U} / \mathrm{m}^{2} \mathrm{IM}$ & $100,107,114,121,128,135$ \\
\hline & $5000 \mathrm{U} / \mathrm{m}^{2} \mathrm{IM}$ & $100,107,114,121,128,135$ \\
\hline Dexamethasone & $6 \mathrm{mg} / \mathrm{m}^{2} \mathrm{PO}$ & $141-151$ \\
\hline Vincristine & $1.5 \mathrm{mg} / \mathrm{m}^{2} \mathrm{IV}$ & 141,148 \\
\hline \multicolumn{3}{|l|}{ Consolidation III } \\
\hline 6-Mercaptopurine & $50 \mathrm{mg} / \mathrm{m}^{2} \mathrm{PO}$ & $155-196$ \\
\hline Methotrexate & $30 \mathrm{mg} / \mathrm{m}^{2} \mathrm{IM}$ & $155,162,169,176,183,190$ \\
\hline \multirow[t]{2}{*}{ E. coli-asparaginase $\mathrm{e}^{\mathrm{c}}$} & $10,000 \mathrm{U} / \mathrm{m}^{2} \mathrm{IM}$ & $156,163,170,177,184,191$ \\
\hline & $5000 \mathrm{U} / \mathrm{m}^{2} \mathrm{IM}$ & $156,163,170,177,184,191$ \\
\hline Dexamethasone & $6 \mathrm{mg} / \mathrm{m}^{2} \mathrm{PO}$ & $197-207$ \\
\hline Vincristine & $1.5 \mathrm{mg} / \mathrm{m}^{2} \mathrm{IV}$ & 197,204 \\
\hline \multicolumn{3}{|c|}{ Preventive CNS therapy (age adjusted) ${ }^{\mathrm{d}}$} \\
\hline Methotrexate IT & $8 / 10 / 12 \mathrm{mg}$ & $1,8,15,22,29,36,85,141,197,253,309,365,421$ \\
\hline Cytarabine IT & $20 / 26 / 30 \mathrm{mg}$ & \\
\hline Prednisone IT & $6 / 8 / 10 \mathrm{mg}$ & \\
\hline CNS radiation therapy & $-($ any age $)$ & \\
\hline \multicolumn{3}{|l|}{ Maintenance therapy } \\
\hline 6-Mercaptopurine (once daily) & $50 \mathrm{mg} / \mathrm{m}^{2} \mathrm{PO}$ & Weeks: $31-36,39-44,47-52,55-60,63-68,71-76,79-84,87-92,95-104$ \\
\hline Methotrexate (once weekly) & $30 \mathrm{mg} / \mathrm{m}^{2} \mathrm{IM}$ & \\
\hline Dexamethasone & $6 \mathrm{mg} / \mathrm{m}^{2} \mathrm{PO}$ & Weeks: $37-38,45-46,53-54,61-62,69-70,77-78,85-86,93-94$ \\
\hline Vincristine & $1.5 \mathrm{mg} / \mathrm{m}^{2} \mathrm{IV} \times 2$ & \\
\hline
\end{tabular}

$A L L-M B 2002$ the protocol acute lymphoblastic leukemia-Moscow-Berlin 2002, BM bone marrow, CNS central nervous system, IM intramuscular, ImRG intermediate risk group, $I T$ intrathecal, $I V$ intravenous, $P O$ per os, $S R G$ standard risk group

Bold indicates the differences in treatment between the two compared groups

${ }^{a}$ Glucocorticoid type according to randomization arm

${ }^{\mathrm{b}}$ Given on day 22 to SRG patients with $\geq 10 \%$ BM blasts on day 15

${ }^{c} \mathrm{~L}$-asparaginase dosage according to randomization arm

${ }^{\mathrm{d}}$ Age adjusted IT doses: $\geq 1-<2$ years $/ \geq 2-<3$ years $/ \geq 3$ years 
many $(n=16)$ patients who received $10,000 \mathrm{U} / \mathrm{m}^{2}$, ASP had to be discontinued. Among patients of arm ASP-5000, the reasons for discontinuation were: HSR $(n=4)$; pancreatitis $(n=2)$ and severe, persistent vomiting $(n=1)$, whereas HSR $(n=13)$ and pancreatitis $(n=3)$ led to discontinuation of ASP for patients in arm ASP-10000. Estimates of DFS "as treated" at 10 years were $80 \pm 2 \%$ in arm ASP- 5 and $74 \pm 2 \%$ in arm ASP-10 $(p(\log$-rank $)=0.11)$; OS probabilities were $86 \pm 2 \%$ and $80 \pm 2 \%$, respectively $\left(p_{\text {log-rank }}=0.06\right)$ (data not shown).

\section{Discussion}

In this randomized multicenter trial across Russia and Belarus, reduction of the ASP dose from $10,000 \mathrm{U} / \mathrm{m}^{2}$ to 5000 $\mathrm{U} / \mathrm{m}^{2} \mathrm{IM}$ did not have any negative effect on the outcome of more than 300 SR pediatric patients with ALL. Estimates of DFS were comparable and side effects, in particular TRM, were seen more frequently in patients who received the higher dose. The DFS of $79 \pm 2 \%$ is similar to that reported by previous studies, in which SR patients comprised only about $30 \%$ of the total cohort compared to $70 \%$ in our study (Schrappe et al. 2000; Pession et al. 2005; Silverman et al. 2010). The weekly dose of $5000 \mathrm{U} / \mathrm{m}^{2} \mathrm{IM}$ proved to be safe and cost-efficient. Therefore, only $5000 \mathrm{U} / \mathrm{m}^{2}$ are being used in subsequent trials in Russia.
Table 2 Patient characteristics by randomization arm

\begin{tabular}{|c|c|c|c|}
\hline Total patients & $\begin{array}{l}\text { Arm ASP-5000 } \\
n=334\end{array}$ & $\begin{array}{l}\text { Arm ASP-10000 } \\
n=354\end{array}$ & $p$ \\
\hline \multicolumn{4}{|l|}{ Gender } \\
\hline Boys & 181 & 192 & \multirow[t]{2}{*}{0.949} \\
\hline Girls & 153 & 162 & \\
\hline \multicolumn{4}{|l|}{ Age (years) } \\
\hline$\geq 1-<5$ & 161 & 189 & \multirow[t]{3}{*}{0.370} \\
\hline$\geq 5-<10$ & 93 & 92 & \\
\hline$\geq 10$ & 80 & 73 & \\
\hline \multicolumn{4}{|l|}{ Initial WBC count } \\
\hline$<10,000 / \mu 1$ & 210 & 227 & \multirow[t]{3}{*}{0.271} \\
\hline$\geq 10,000-<30,000 / \mu 1$ & 102 & 94 & \\
\hline$\geq 30,000-<50,000 / \mu 1$ & 22 & 33 & \\
\hline \multicolumn{4}{|c|}{ Spleen enlargement below left costal margin $(\mathrm{cm})$} \\
\hline$<4$ & 258 & 256 & \multirow[t]{2}{*}{0.162} \\
\hline$\geq 4$ & 76 & 98 & \\
\hline \multicolumn{4}{|l|}{ Genetics $^{\mathrm{a}}$} \\
\hline$t(12 ; 21)$ & 29 & 24 & 0.491 \\
\hline \multicolumn{4}{|l|}{ Response to treatment on day $8^{\mathrm{b}}$} \\
\hline$<1000$ leukemic blasts/ $\mu \mathrm{l}$ PB & 318 & 331 & \multirow[t]{2}{*}{0.473} \\
\hline$\geq 1000$ leukemic blasts/ $\mu \mathrm{l}$ PB & 9 & 14 & \\
\hline \multicolumn{4}{|l|}{ Response to treatment on day $15^{\mathrm{c}}$} \\
\hline$<10 \%$ leukemic blasts in $\mathrm{BM}$ & 272 & 285 & \multirow[t]{3}{*}{0.790} \\
\hline$\geq 10-<25 \%$ leukemic blasts in $\mathrm{BM}$ & 40 & 39 & \\
\hline$\geq 25 \%$ leukemic blasts in $\mathrm{BM}$ & 19 & 24 & \\
\hline \multicolumn{4}{|l|}{ Induction therapy } \\
\hline Dexamethasone $6 \mathrm{mg} / \mathrm{m}^{2}$ & 168 & 176 & \multirow[t]{2}{*}{0.874} \\
\hline Methylprednisolone $60 \mathrm{mg} / \mathrm{m}^{2}$ & 163 & 177 & \\
\hline
\end{tabular}

$A S P$ asparaginase, $B M$ bone marrow, $I M$ intramuscular, $P B$ peripheral blood, $W B C$ white blood cell count

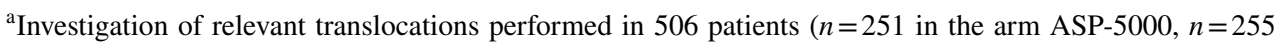
in the arm ASP-10000)

${ }^{\mathrm{b}}$ Treatment response on day 8 was documented for 672 patients (327 patients in the arm ASP-5000, 345 patients in the arm ASP-10000)

${ }^{\mathrm{c}}$ Treatment response on day 15 was documented for 679 patients (331 patients in the arm ASP-5000, 348 patients in the arm ASP-10000) 
Nevertheless, the results of this trial raise some important questions. ASP preparations have been used at a wide variety of dosages starting at $5000 \mathrm{U} / \mathrm{m}^{2}$, in early trials even at lower or higher doses up to $30,000 \mathrm{U} / \mathrm{m}^{2}$, at different time intervals and also via varying routes of administration (Pession et al. 2005; Muller and Boos 1998; Albertsen et al. 2001; Schrey et al. 2010). The mechanism of action associated with antileukemic ASP treatment is the ASP-provided hydrolyzation of asparagine (ASN) in the patient's plasma. It is assumed that complete and sustained ASN depletion is required to achieve optimal ASP treatment effects. Monitoring ASP activity or asparagine levels, respectively, has been performed with conflicting results: According to most reports, trough levels of ASP should not fall below $100 \mathrm{U} / \mathrm{L}$ in order to achieve "complete" depletion but even lower levels, $<50 \mathrm{U} / \mathrm{L}$, were suggested to be sufficient by others (Boos et al. 1996; Riccardi et al. 1981; Rizzari et al. 2000). Thus, the exactly required minimum serum enzyme activity remains unclear. In addition, there is still uncertainty about the extent of ASN depletion. On the one hand, the accuracy of monitoring ASN levels depends on the sensitivity of the method, which is limited; on the other hand, monitoring data may not be valid after all, because ASN depletion does continue in vitro after blood sampling, despite immediate cooling (Lanvers-Kaminsky et al. 2014). If "complete" depletion is a realistic option, it is not clear whether this should be achieved during induction or as part of post-induction therapy or both.

Usually, ASP is part of the induction therapy, but has been used for intensification during consolidation and maintenance therapy as well. About $10 \%$ improvement in EFS was reported by the administration of 20 additional weekly doses of (predominantly) Erwinia-ASP during maintenance therapy in SR patients (Pession et al. 2005). In contrast, no positive effect on outcome was seen after high-dose ASP in SR patients in a Dutch study (Kamps et al. 2002). Also, no advantage was shown after additional administration of Erwinia-ASP during maintenance in intermediate risk patients or E. coli-ASP during consolidation therapy in another study, respectively (Schrappe et al. 2000; Rizzari et al. 2001).

In addition to the question during which phase of therapy ASN depletion is relevant, it is not clear for what period of time it is required. Based on the currently available data, permanent trough levels of $\geq 100 \mathrm{IU} / \mathrm{L}$ can most likely be achieved with ASP at a dose of $5000 \mathrm{U} / \mathrm{m}^{2} \mathrm{IV}$ three times weekly (Schrey et al. 2010).

Unfortunately, no prospective controlled study comparing the pharmacology after IV vs. IM E. coli-ASP has been published yet. Comparison of IV PEG-ASP with IM E. coliASP showed similar efficacy and toxicity, but the IV route was associated with decreased anxiety (Place et al. 2015). The recommended dose of native E. coli-ASP is $5000 \mathrm{U} /$ $\mathrm{m}^{2}$ per injection site corresponding to a volume of $2 \mathrm{ml}$. It is not surprising that IM injections of higher doses are not appreciated by pediatric patients. Nevertheless, reliable data comparing the pharmacology of IM and IV administered ASP are lacking. In a recent report, about $20 \%$ of patients who received $25,000 \mathrm{U} / \mathrm{m}^{2}$ native $E$. coli-ASP IM weekly had nadir serum ASP activities lower than $100 \mathrm{U} / \mathrm{L}$ (Vrooman et al. 2013). Thus, permanent and complete depletion can hardly be expected in all patients. Likewise, sustained and complete ASN depletion cannot be expected after IM administration of $25,000 \mathrm{U} / \mathrm{m}^{2}$ Erwinia-ASP because of its inferior activity compared with E. coli-ASP (Pession et al. 2005; Asselin et al. 1993; Duval et al. 2002). A general question remains whether "total" ASN depletion with the consequence of inhibiting protein synthesis might diminish the sensitivity of leukemic cells to other cytotoxic drugs.

The purpose of this study was not to investigate the pharmacokinetics of ASP. Hence, ASP activities were not routinely monitored during the course of our study. However, in the subsequent trial ALL-MB 2008, serum samples have been randomly collected and enzyme activities measured in Muenster (Prof. Boos). As shown in supplementary Fig. 2a and $2 \mathrm{~b}$, ASP trough levels (day 7) were far below $100 \mathrm{U} / \mathrm{L}$ in most patients. Thus, in the MB regimen, the supposedly required trough levels of ASP activity are neither achieved after $5000 \mathrm{U} / \mathrm{m}^{2}$ nor after $10,000 \mathrm{U} / \mathrm{m}^{2}$. Since the DFS and OS results in our study correspond to international published data in SR patients, we may conclude that sustained trough levels of $\geq 100 \mathrm{U} / \mathrm{L}$ ASP activity may not be necessary for the antileukemic efficacy of the drug. Alternatively, one could question whether in context with the MB protocol

Table 3 Treatment results by randomization arm

\begin{tabular}{|c|c|c|c|c|c|}
\hline & \multicolumn{2}{|c|}{ Arm ASP-5000 } & \multicolumn{2}{|c|}{$\begin{array}{l}\text { Arm ASP- } \\
10000\end{array}$} & \multirow[t]{2}{*}{$p$} \\
\hline & $n$ & $\%$ & $n$ & $\%$ & \\
\hline Total patients & 334 & 100 & 354 & 100 & \\
\hline All relapses & 58 & 17.4 & 63 & 17.8 & 0.961 \\
\hline \multicolumn{6}{|l|}{ Site } \\
\hline Bone marrow & 37 & 11.1 & 33 & 9.3 & 0.525 \\
\hline CNS & 5 & 1.5 & 10 & 2.8 & 0.352 \\
\hline Testis & 1 & 0.3 & 4 & 1.1 & 0.405 \\
\hline $\mathrm{BM}+\mathrm{CNS}$ & 12 & 3.6 & 12 & 3.4 & 0.950 \\
\hline $\mathrm{BM}+$ testis & 3 & 0.9 & 4 & 1.1 & 0.938 \\
\hline Other & 0 & 0.0 & 0 & 0.0 & - \\
\hline Secondary malignancy & 2 & 0.6 & 2 & 0.6 & 0.658 \\
\hline Death in CR & 9 & 2.7 & 23 & 6.5 & 0.029 \\
\hline LFU & 5 & 1.5 & 9 & 2.5 & 0.389 \\
\hline Continuous CR & 260 & $\mathbf{7 7 . 8}$ & 257 & 72.6 & 0.115 \\
\hline
\end{tabular}

$A S P$ asparaginase, $B M$ bone marrow, $C N S$ central nervous system, $C R$ complete remission, $I M$ intramuscular, $L F U$ lost to follow-up 
design, ASP is necessary at all-an assumption which is rather unlikely, however.

Nevertheless, despite the relatively low dose of ASP, the weekly dosing regimen and the large size of the SR group (70\% of the total cohort), the DFS rate of $80 \%$ in this study is high when compared to other trials using much higher doses of ASP. One reason might be that we used only Asparaginase medac $^{\mathrm{TM}}$, which has been shown to be the most potent $E$. coli-ASP preparation (Boos et al. 1996; Rizzari et al. 2000). Another explanation might be the exceedingly low rate of allergic reactions in our study. HSR have been significantly more frequent after IV than IM administration-even if PEG-ASP was used (Nesbit et al. 1979; Petersen et al. 2014; Henriksen et al. 2015; Abbott et al. 2015; van der Sluis et al. 2016). Frequently, HSR to ASP are accompanied by silent inactivation, and a lower rate of such events may have contributed to the result of our study (van der Sluis et al. 2016; Asselin and Rizzari 2015). In a study of the Dana-Farber Cancer Institute (DFCI), independent positive effects were seen after post-induction DEXA and individualized dosing
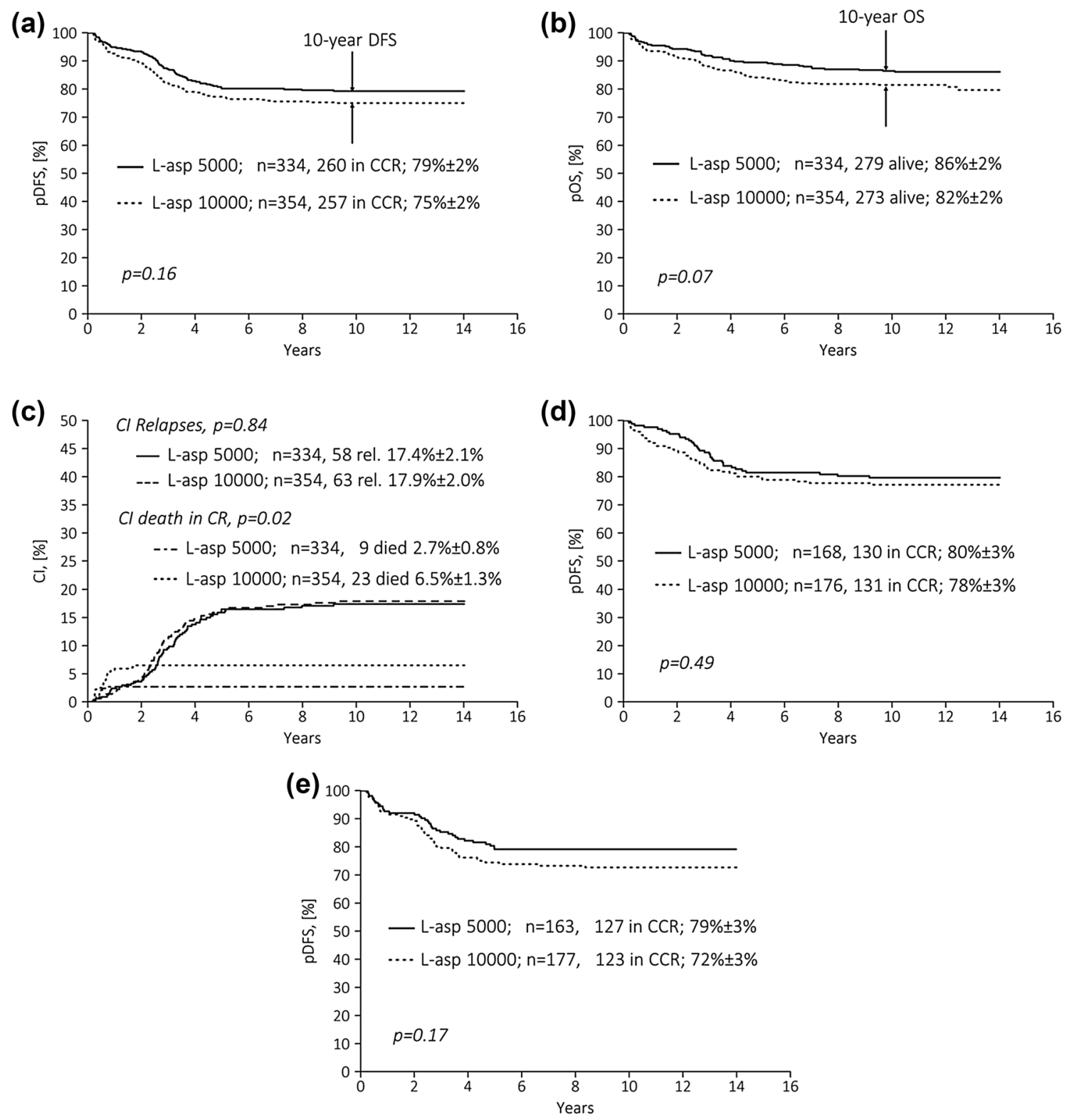

Fig. 2 Treatment results ("intent-to-treat-analysis") for standard risk group patients after consolidation therapy with 5000 vs. $10,000 \mathrm{U} / \mathrm{m}^{2}$ of E. coli-ASP IM in trial ALL-Moscow-Berlin 2002 by randomization arm (for details, see main text). a Disease-free survival (DFS) at 10 years, b probability of overall survival (pOS) at 10 years, c cumulative incidence $(\mathrm{CI})$ of relapses and deaths in $\mathrm{CR}$ at 10 years. d Disease-free survival (DFS) at 10 years only patients randomized to DEXA during induction, e disease-free survival (DFS) at 10 years only patients randomized to MePRED during induction. ASP asparaginase, $C I$ cumulative incidence, $C R$ complete remission, $C C R$ continuous CR, DFS disease-free survival, $I M$ intramuscular, $p O S$ probability of overall survival 
of $E$. coli-ASP (Vrooman et al. 2013); in this context, the frequent use of DEXA in our protocol could also have had a positive effect on outcome.

Toxicity, in particular TRM, was more frequent in the ASP-10000 arm. Although ASP is assumed not to have substantial hematological toxicity, a myelosuppressive effect of prolonged ASP therapy in consolidation requiring dose reductions of other critical chemotherapy agents has been reported (Merryman et al. 2012). Also, myelosuppressive effects of ASP in part interfering with antimetabolite therapy have been described earlier (Johnston et al. 1974; Salzer et al. 2007; Hijiya and van der Sluis 2016). Hematological toxicity, though not in detail documented in our trial, may represent a contributing factor to the increased late, mostly infection-related, TRM in the ASP-10000 arm as described above. As far as toxicity is concerned, a synergistic effect between ASP and glucocorticoids, in particular DEXA, has been described (Liu et al. 2016). The authors concluded from their studies in mice that ASP can potentiate the osteonecrotic effects of glucocorticoids. Epiphyseal arteriopathy, an initiating event for osteonecrosis, was observed in 58\% of mice receiving ASP and DEXA compared to $17 \%$ of mice receiving DEXA only. Previously, we have described a very low incidence of avascular necrosis of bone (AVN) despite high cumulative doses of DEXA in our protocol (Karachunskiy et al. 2015). In context with the observed association between ASP and avascular necrosis (AVN), this may be explained by the modest dose of $6 \mathrm{mg} / \mathrm{m}^{2}$ DEXA and the limited use of ASP.

Overall, our study confirms that numerous questions concerning ASP therapy are still open. Reports of clinical trials and also overviews should always clearly indicate the source of the drugs used, as well as the dose, route of administration, dosing intervals, and details of the chemotherapy protocol to allow valid comparisons and interpretations. According to a recent consensus, the most reliable parameter to assess clinical effects is monitoring of ASP serum activity after defined time intervals (van der Sluis et al. 2016). If necessary, therapy could then be adapted to individual metabolism and tolerance.

The regimen used in this study proved to be effective in SR patients comprising $70 \%$ of the total group and defined by the very simple stratification system. If we applied the refined stratification of the subsequent trial ALL-MB 2008, the SR group would be reduced to $50 \%$ of the total group, and for these patients, DFS would yield $86 \pm 3 \%$ for the ASP-5000 arm (Suppl. Fig. 3A). Comparably favorable DFS rates can be calculated when stratifying our SRG patients according to SR criteria used by the International BerlinFrankfurt-Muenster-(IBFM) group (Suppl. Fig. 3B) or by the DFCI (Suppl. Fig. 3C), respectively. Of note, the MB protocol contained very moderate anthracycline doses and no high-dose or substantially cytotoxic therapies, e.g., HD methotrexate or cyclophosphamide.

Table 4 Characteristics and outcomes of SRG patients in the ALL-Moscow-Berlin 2002 trial by randomization arm

\begin{tabular}{|c|c|c|c|c|c|c|}
\hline & \multicolumn{2}{|c|}{ Disease-free survival (DFS) } & \multirow[t]{2}{*}{$p$} & \multicolumn{2}{|c|}{ Overall survival (OS) } & \multirow[t]{2}{*}{$p$} \\
\hline & Arm ASP-5000 & Arm ASP-10000 & & Arm ASP-5000 & Arm ASP-10000 & \\
\hline \multicolumn{7}{|l|}{ Gender } \\
\hline Boys & $80 \pm 3 \%$ & $72 \pm 3 \%$ & $\mathbf{0 . 0 3}$ & $84 \pm 4 \%$ & $81 \pm 3 \%$ & $\mathbf{0 . 0 5}$ \\
\hline Girls & $78 \pm 3 \%$ & $80 \pm 3 \%$ & 0.81 & $84 \pm 3 \%$ & $83 \pm 3 \%$ & 0.83 \\
\hline \multicolumn{7}{|l|}{ Age (years) } \\
\hline$\geq 1-<5$ & $84 \pm 3 \%$ & $79 \pm 3 \%$ & 0.20 & $88 \pm 4 \%$ & $83 \pm 3 \%$ & $\mathbf{0 . 0 4}$ \\
\hline$\geq 5-<10$ & $78 \pm 4 \%$ & $76 \pm 4 \%$ & 0.72 & $83 \pm 4 \%$ & $85 \pm 4 \%$ & 0.70 \\
\hline$\geq 10$ & $70 \pm 5 \%$ & $63 \pm 6 \%$ & 0.27 & $80 \pm 5 \%$ & $74 \pm 5 \%$ & 0.23 \\
\hline \multicolumn{7}{|l|}{ Initial white blood cell count } \\
\hline$<10,000 / \mu \mathrm{l}$ & $80 \pm 3 \%$ & $76 \pm 3 \%$ & 0.25 & $85 \pm 3 \%$ & $83 \pm 3 \%$ & 0.23 \\
\hline$\geq 10,000-<30,000 / \mu \mathrm{l}$ & $78 \pm 4 \%$ & $77 \pm 4 \%$ & 0.82 & $81 \pm 6 \%$ & $84 \pm 4 \%$ & 0.78 \\
\hline$\geq 30,000-<50,000 / \mu 1$ & $77 \pm 9 \%$ & $64 \pm 8 \%$ & 0.28 & $86 \pm 7 \%$ & $70 \pm 8 \%$ & 0.16 \\
\hline \multicolumn{7}{|l|}{ Genetics } \\
\hline$t(12 ; 21)$ & $93 \pm 5 \%$ & $88 \pm 7 \%$ & 0.51 & $83 \pm 13 \%$ & $100 \pm 0 \%$ & 0.24 \\
\hline \multicolumn{7}{|l|}{ Induction therapy } \\
\hline Dexamethasone $6 \mathrm{mg} / \mathrm{m}^{2}$ & $80 \pm 3 \%$ & $78 \pm 3 \%$ & 0.49 & $84 \pm 3 \%$ & $83 \pm 3 \%$ & 0.42 \\
\hline Methylprednisolone $60 \mathrm{mg} / \mathrm{m}^{2}$ & $79 \pm 3 \%$ & $72 \pm 3 \%$ & 0.17 & $85 \pm 4 \%$ & $80 \pm 3 \%$ & 0.12 \\
\hline
\end{tabular}

DFS was significantly superior in boys, and OS higher in boys and young children (aged $\geq 1-<5$ years) in the arm ASP-5000 than in the arm ASP-10000. DFS was independent of other patient characteristics shown, in particular of the glucocorticoid used during induction (Dexamethasone vs. Methylprednisolone)

Statistical significant $p$ values are in bold 
Table 5 Treatment-related death (TRD) of patients with standard-risk childhood acute lymphoblastic leukemia (ALL) in complete remission (CR) in the ALL-Moscow-Berlin 2002 trial by randomization arm

\begin{tabular}{|c|c|c|c|c|c|}
\hline & \multicolumn{2}{|c|}{ Arm ASP-5000 } & \multicolumn{2}{|c|}{ Arm ASP-10000 } & \multirow[t]{2}{*}{$P_{\text {Fisher }}$} \\
\hline & $n$ & $\%$ & $n$ & $\%$ & \\
\hline TRD in CR & 9 & 100 & 23 & 100 & 0.029 \\
\hline \multicolumn{6}{|l|}{ Time of death } \\
\hline $\begin{array}{l}\text { Day of therapy, } \\
\text { median [interquartile } \\
\text { range] }\end{array}$ & \multicolumn{2}{|c|}{158 [116-163] } & \multicolumn{2}{|c|}{220 [100-264.75] } & 0.213 \\
\hline Consolidation I & 4 & 44.4 & 8 & 34.8 & 0.696 \\
\hline Consolidation II & 3 & 33.3 & 1 & 4.3 & 0.057 \\
\hline Consolidation III & 1 & 11.1 & 8 & 34.8 & 0.383 \\
\hline Maintenance therapy & 1 & 11.1 & 6 & 26.1 & 0.640 \\
\hline
\end{tabular}

TRD in CR occurred significantly less frequently in arm ASP-5000 (9/334 patients) than arm ASP-10000 (23/354 patients). In arm ASP10000 , more than $60 \%$ of TRD were seen late (in consolidation III and maintenance therapy), whereas about $80 \%$ of TRD in arm ASP5000 occurred early (during consolidation I and II)

Statistical significant $p$ values are in bold

In summary, the ASP dose of $5000 \mathrm{U} / \mathrm{m}^{2}$ was not associated with inferior results compared to $10,000 \mathrm{U} / \mathrm{m}^{2}$. HSR rates and adverse effects were overall low in both arms. IM-injection volumes were moderate and well tolerated. Favorable results were achieved with the lower ASP dose at defined dosing intervals. Critical evaluation of the results suggests that some assumptions concerning duration and completeness of ASN depletion and correspondingly required enzyme levels do not match current opinions and principles. Obviously, it is possible to reduce the ASP dose if the overall antileukemic power of the protocol is high. With respect to cure rates as well as economical and ethical considerations, such as preventing toxicity and being aware of cost-efficiency, the ASP-5000 arm in context with the MB treatment design is a reasonable therapeutic approach for pediatric patients with SR-ALL—not only in countries with limited resources.

Acknowledgements We thank all the members of the charity organization Kontakty-Kontakte e.V., Berlin, in particular project manager Eberhard Radczuweit, for continuous comprehensive support of our efforts to conduct this multicenter trial in Russia. We also thank all the pediatric oncologists and laboratory coworkers from the participating centers involved, the patients and families, colleagues, especially Svetlana Plyasunova, Maria Dubrovina, Olga Fuks, Inna Gerbek, Natalia Grigorieva, Lyudmila Minkina, Marina Postoikina, Olga Tselousova, Tatiana Asekretova, Natalia Chaplygina, Alexander Beznoshchenko, Valentina Timofeeva for their cooperation.

Author contributions AK: designed research, performed research, collected and analyzed data. GT: analyzed and interpreted data, and wrote manuscript. JR: collected and analyzed data, and performed statistical analysis. SL: collected and analyzed data. AC: performed statistical analysis and pharmacokinetics. AS: Designed research. OA: Collected data and designed research. OB: Performed statistical analysis. LB: Performed immune phenotyping. TN: Performed molecular genetics. NK: Performed statistical analysis. SK: Performed statistical analysis. GN: Collected data and designed research. MG: Collected data. DL: Collected data. NM: Collected data and designed research. NP: Collected data. EI: Collected data. KK: Collected data. JA: Collected data. LF: Collected data and designed research. OA: Collected data. AK: Collected data. VL: Collected data. NJ: Collected data. GS: Collected data. IS: Collected data. AS: Collected data and designed research. OR: Collected data. AS: Collected data. AR: Designed research. JB: designed research, collected data, and wrote manuscript. GH: designed research, wrote manuscript, and statistical analysis.

Funding This work was fully supported by the charity organization 'Kontakty-Kontakte e.V.' (Project title 'Kinderleukämie'), Berlin, Germany.

\section{Compliance with ethical standards}

Conflict of interest The authors declare no conflict of interest.

Open Access This article is distributed under the terms of the Creative Commons Attribution 4.0 International License (http://creativeco mmons.org/licenses/by/4.0/), which permits unrestricted use, distribution, and reproduction in any medium, provided you give appropriate credit to the original author(s) and the source, provide a link to the Creative Commons license, and indicate if changes were made.

\section{References}

Abbott LS, Zakova M, Shaikh F, Shewaramani N, Punnett A, Dupuis LL (2015) Allergic reactions associated with intravenous versus intramuscular pegaspargase: a retrospective chart review. Paediatr Drugs 17(4):315-321. https://doi.org/10.1007/s40272-015-0129-1

Albertsen BK, Schroder H, Jakobsen P, Muller HJ, Carlsen NT, Schmiegelow K (2001) Monitoring of Erwinia asparaginase therapy in childhood ALL in the Nordic countries. Br J Clin Pharmacol 52(4):433-437

Alrazzak M, Beaupin LK, Kinyoun P, Barth M (2016) The Incidence of hypersensitivity reactions to pegylated asparaginase in children with acute lymphoblastic leukemia: a city-wide experience. J Pediatr Hematol Oncol 38(1):e16-e20. https:// doi.org/10.1097/MPH.0000000000000465

Asselin B, Rizzari C (2015) Asparaginase pharmacokinetics and implications of therapeutic drug monitoring. Leuk Lymphoma 56(8):2273-2280. https://doi.org/10.3109/10428 194.2014.1003056

Asselin BL, Whitin JC, Coppola DJ, Rupp IP, Sallan SE, Cohen HJ (1993) Comparative pharmacokinetic studies of three asparaginase preparations. J Clin Oncol 11(9):1780-1786. https://doi. org/10.1200/JCO.1993.11.9.1780

Beaupin LK, Bostrom B, Barth MJ et al (2017) Pegaspargase hypersensitivity reactions: intravenous infusion versus intramuscular injection-a review. Leuk Lymphoma 58(4):766-772. https:// doi.org/10.1080/10428194.2016.1218004

Boos J, Werber G, Ahlke E et al (1996) Monitoring of asparaginase activity and asparagine levels in children on different asparaginase preparations. Eur J Cancer 32A(9):1544-1550

Clavell LA, Gelber RD, Cohen HJ et al (1986) Four-agent induction and intensive asparaginase therapy for treatment of childhood acute lymphoblastic leukemia. N Engl J Med 315(11):657-663. https://doi.org/10.1056/NEJM198609113151101 
Duval M, Suciu S, Ferster A et al (2002) Comparison of Escherichia coli-asparaginase with Erwinia-asparaginase in the treatment of childhood lymphoid malignancies: results of a randomized European Organisation for Research and Treatment of Cancer-Children's Leukemia Group phase 3 trial. Blood 99(8):2734-2739

Henriksen LT, Harila-Saari A, Ruud E et al (2015) PEG-asparaginase allergy in children with acute lymphoblastic leukemia in the NOPHO ALL2008 protocol. Pediatr Blood Cancer 62(3):427433. https://doi.org/10.1002/pbc. 25319

Hijiya N, van der Sluis IM (2016) Asparaginase-associated toxicity in children with acute lymphoblastic leukemia. Leuk Lymphoma 57(4):748-757. https://doi.org/10.3109/10428194.2015.1101098

Ho DH, Yap HY, Brown N, Benjamin RS, Blumenschein GR, Bodey GP (1981) Clinical pharmacology of intramuscularly administered L-asparaginase. J Clin Pharmacol 21(2):72-78

Johnston PG, Hardisty RM, Kay HE, Smith PG (1974) Myelosuppressive effect of colaspase (L-asparaginase) in initial treatment of acute lymphoblastic leukaemia. Br Med J 3(5923):81-83

Kamps WA, Bokkerink JP, Hakvoort-Cammel FG et al (2002) BFMoriented treatment for children with acute lymphoblastic leukemia without cranial irradiation and treatment reduction for standard risk patients: results of DCLSG protocol ALL-8 (1991-1996). Leukemia 16(6):1099-1111. https://doi.org/10.1038/sj.leu.2402489

Karachunskiy A, Herold R, von Stackelberg A et al (2008) Results of the first randomized multicentre trial on childhood acute lymphoblastic leukaemia in Russia. Leukemia 22(6):1144-1153. https:// doi.org/10.1038/leu.2008.63

Karachunskiy A, Roumiantseva J, Lagoiko S et al (2015) Efficacy and toxicity of dexamethasone vs methylprednisolone-long-term results in more than 1000 patients from the Russian randomized multicentric trial ALL-MB 2002. Leukemia 29(9):1955-1958. https://doi.org/10.1038/leu.2015.63

Ko RH, Jones TL, Radvinsky D et al (2015) Allergic reactions and antiasparaginase antibodies in children with high-risk acute lymphoblastic leukemia: a children's oncology group report. Cancer 121(23):4205-4211. https://doi.org/10.1002/cncr.29641

Kolarz G, Pietschmann H (1971) Leukocytic changes under treatment with L-asparaginase. Wien Med Wochenschr 121(11):196-199

Lanvers-Kaminsky C, Westhoff PS, D'Incalci M, Zucchetti M, Boos J (2014) Immediate cooling does not prevent the ex vivo hydrolysis of L-asparagine by asparaginase. Ther Drug Monit 36(4):549-552. https://doi.org/10.1097/FTD.0000000000000030

Liu C, Janke LJ, Kawedia JD et al (2016) Asparaginase potentiates glucocorticoid-induced osteonecrosis in a mouse model. PLoS One 11(3):e0151433. https://doi.org/10.1371/journal.pone.0151433

Merryman R, Stevenson KE, Gostic WJ 2nd, Neuberg D, O'Brien J, Sallan SE, Silverman LB (2012) Asparaginase-associated myelosuppression and effects on dosing of other chemotherapeutic agents in childhood acute lymphoblastic leukemia. Pediatr Blood Cancer 59(5):925-927. https://doi.org/10.1002/pbc.24182

Muller HJ, Boos J (1998) Use of L-asparaginase in childhood ALL. Crit Rev Oncol Hematol 28(2):97-113

Narta UK, Kanwar SS, Azmi W (2007) Pharmacological and clinical evaluation of L-asparaginase in the treatment of leukemia. Crit Rev Oncol Hematol 61(3):208-221. https://doi.org/10.1016/j.critr evonc.2006.07.009

Nesbit M, Chard R, Evans A, Karon M, Hammond GD (1979) Evaluation of intramuscular versus intravenous administration of $\mathrm{L}$-asparaginase in childhood leukemia. Am J Pediatr Hematol Oncol 1(1):9-13

Oehlers MJ, Fetawadjieff W, Woodliff HJ (1969) Profound leukopenia following asparaginase treatment in a patient with acute lymphoblastic leukaemia. Med J Aust 2(18):907-909

Oettgen HF, Old LJ, Boyse EA et al (1967) Inhibition of leukemias in man by L-asparaginase. Cancer Res 27(12):2619-2631
Pession A, Valsecchi MG, Masera G et al (2005) Long-term results of a randomized trial on extended use of high dose L-asparaginase for standard risk childhood acute lymphoblastic leukemia. J Clin Oncol 23(28):7161-7167. https://doi.org/10.1200/ JCO.2005.11.411

Petersen WC Jr, Clark D, Senn SL, Cash WT, Gillespie SE, McCracken CE, Keller FG, Lew G (2014) Comparison of allergic reactions to intravenous and intramuscular pegaspargase in children with acute lymphoblastic leukemia. Pediatr Hematol Oncol 31(4):311-317. https://doi.org/10.3109/08880018.2013.876134

Pieters R, Hunger SP, Boos J et al (2011) L-asparaginase treatment in acute lymphoblastic leukemia: a focus on Erwinia asparaginase. Cancer 117(2):238-249. https://doi.org/10.1002/cncr.25489

Place AE, Stevenson KE, Vrooman LM et al (2015) Intravenous pegylated asparaginase versus intramuscular native Escherichia coli L-asparaginase in newly diagnosed childhood acute lymphoblastic leukaemia (DFCI 05-001): a randomised, open-label phase 3 trial. Lancet Oncol 16(16):1677-1690. https://doi.org/10.1016/ S1470-2045(15)00363-0

Riccardi R, Holcenberg JS, Glaubiger DL, Wood JH, Poplack DG (1981) L-asparaginase pharmacokinetics and asparagine levels in cerebrospinal fluid of rhesus monkeys and humans. Cancer Res 41(11 Pt 1):4554-4558

Rizzari C (2015) Still trying to pick the best asparaginase preparation. Lancet Oncol 16(16):1580-1581. https://doi.org/10.1016/S1470 -2045(15)00451-9

Rizzari C, Zucchetti M, Conter V et al (2000) L-asparagine depletion and L-asparaginase activity in children with acute lymphoblastic leukemia receiving i.m. or i.v. Erwinia C. or E. coli L-asparaginase as first exposure. Ann Oncol 11(2):189-193

Rizzari C, Valsecchi MG, Arico M et al (2001) Effect of protracted high-dose L-asparaginase given as a second exposure in a BerlinFrankfurt-Munster-based treatment: results of the randomized 9102 intermediate-risk childhood acute lymphoblastic leukemia study - a report from the Associazione Italiana Ematologia Oncologia Pediatrica. J Clin Oncol 19(5):1297-1303. https://doi. org/10.1200/JCO.2001.19.5.1297

Rizzari C, Citterio M, Zucchetti M et al (2006) A pharmacological study on pegylated asparaginase used in front-line treatment of children with acute lymphoblastic leukemia. Haematologica 91(1):24-31

Rizzari C, Conter V, Stary J, Colombini A, Moericke A, Schrappe M (2013) Optimizing asparaginase therapy for acute lymphoblastic leukemia. Curr Opin Oncol 25(Suppl 1):S1-S9. https://doi. org/10.1097/CCO.0b013e32835d7d85

Salzer WL, Devidas M, Shuster JJ et al (2007) Intensified PEG-L-asparaginase and antimetabolite-based therapy for treatment of higher risk precursor-B acute lymphoblastic leukemia: a report from the Children's Oncology Group. J Pediatr Hematol Oncol 29(6):369-375. https://doi.org/10.1097/MPH.0b013e3180640d54

Schmiegelow K, Attarbaschi A, Barzilai S et al (2016) Consensus definitions of 14 severe acute toxic effects for childhood lymphoblastic leukaemia treatment: a Delphi consensus. Lancet Oncol 17(6):e231-e239. https://doi.org/10.1016/S1470-2045(16)30035 $-3$

Schrappe M, Reiter A, Zimmermann M et al (2000) Long-term results of four consecutive trials in childhood ALL performed by the ALL-BFM study group from 1981 to 1995 . Berlin-FrankfurtMunster. Leukemia 14(12):2205-2222

Schrey D, Borghorst S, Lanvers-Kaminsky C, Hempel G, Gerss J, Moricke A, Schrappe M, Boos J (2010) Therapeutic drug monitoring of asparaginase in the ALL-BFM 2000 protocol between 2000 and 2007. Pediatr Blood Cancer 54(7):952-958. https://doi. org/10.1002/pbc.22417

Silverman LB, Stevenson KE, O'Brien JE et al (2010) Long-term results of Dana-Farber Cancer Institute ALL Consortium 
protocols for children with newly diagnosed acute lymphoblastic leukemia (1985-2000). Leukemia 24(2):320-334. https://doi. org/10.1038/leu.2009.253

Tong WH, Pieters R, Kaspers GJ et al (2014) A prospective study on drug monitoring of PEGasparaginase and Erwinia asparaginase and asparaginase antibodies in pediatric acute lymphoblastic leukemia. Blood 123(13):2026-2033. https://doi.org/10.1182/blood -2013-10-534347

van der Sluis IM, Vrooman LM, Pieters R et al (2016) Consensus expert recommendations for identification and management of asparaginase hypersensitivity and silent inactivation. Haematologica 101(3):279-285. https://doi.org/10.3324/haematol.2015.137380
Vrooman LM, Stevenson KE, Supko JG et al (2013) Postinduction dexamethasone and individualized dosing of Escherichia Coli L-asparaginase each improve outcome of children and adolescents with newly diagnosed acute lymphoblastic leukemia: results from a randomized study-Dana-Farber Cancer Institute ALL Consortium Protocol 00-01. J Clin Oncol 31(9):1202-1210. https://doi. org/10.1200/JCO.2012.43.2070

Publisher's Note Springer Nature remains neutral with regard to jurisdictional claims in published maps and institutional affiliations.

\section{Affiliations}

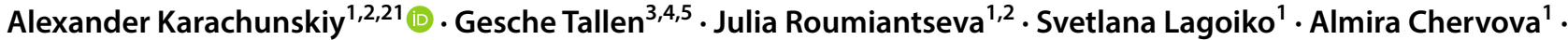 Arend von Stackelberg ${ }^{3}$. Olga Aleinikova ${ }^{6}$. Oleg Bydanov ${ }^{6} \cdot$ Lyudmila Bajdun $^{7}$. Tatiana Nasedkina ${ }^{1}$. Natalia Korepanova ${ }^{8} \cdot$ Sergei Kuznetsov $^{8} \cdot$ Galina Novichkova $^{1,2} \cdot$ Marina Goroshkova $^{9} \cdot$ Dmitry Litvinov $^{1,2}$. Natalia Myakova ${ }^{1}$. Natalia Ponomareva ${ }^{7}$. Evgeniya Inyushkina ${ }^{10} \cdot$ Konstantin Kondratchik $^{2,11}$. Julia Abugova ${ }^{1}$. Larisa Fechina ${ }^{12}$. Oleg Arakaev ${ }^{12}$. Alexander Karelin ${ }^{1}$. Vladimir Lebedev ${ }^{13}$. Natalia Judina ${ }^{14}$. Gusel Scharapova ${ }^{15}$. Irina Spichak ${ }^{16}$. Anastasia Shamardina ${ }^{17}$. Olga Ryskal ${ }^{18}$. Alexander Shapochnik ${ }^{19}$. Alexander Rumjanzew ${ }^{1,2}$. Joachim Boos $^{20}$. Günter Henze ${ }^{2,3}$. for the ALL-MB study group}

1 Federal Research Centre of Pediatric Hematology, Oncology and Immunology, Moscow, Russia

2 Department of Oncology, Hematology and Radiotherapy, Pirogov Russian National Research Medical University, Moscow, Russia

3 Department of Pediatric Oncology/Hematology, Charité-Universitätsmedizin Berlin, Berlin, Germany

4 Department of Pediatric Oncology/Hematology, Universitätsklinikum Hamburg-Eppendorf, Hamburg, Germany

5 Department of Paediatrics, Cumming School of Medicine, Faculty of Medicine, University of Calgary, Calgary, Canada

6 Republic Clinical Research Centre for Pediatric Oncology and Hematology, Minsk, Belarus

7 Russian Children Clinical Hospital, Moscow, Russia

8 National Research University Higher School of Economics, Moscow, Russia

9 Department of Pediatric Hematology, Municipal Children,s Clinical Hospital, Novokuznetsk, Russia

10 Moscow Regional Oncological Dispensary, Balashikha, Russia

11 Department of Pediatric Hematology, Morozov Children's Hospital, Moscow, Russia
12 Paediatric Oncohematological Centre, Regional Children's Hospital, Ekaterinburg, Russia

13 Department of Pediatric Oncology/Hematology, Regional Children's Hospital, Krasnodar, Russia

14 Department of Pediatric Oncology/Hematology, Regional Children's Hospital, Voronezh, Russia

15 Department of Pediatric Oncology/Hematology, Regional Children's Hospital, Nizhnevartovsk, Russia

16 Paediatric Oncohematological Centre, Regional Children's Hospital, Chelyabinsk, Russia

17 Department of Pediatric Hematology, Regional Children's Hospital, Nizhniy Novgorod, Russia

18 Department of Pediatric Oncology/Hematology, Regional Children's Hospital, Perm, Russia

19 Department of Pediatric Oncology/Hematology, Regional Oncological Hospital, Orenburg, Russia

20 Department of Pediatric Hematology and Oncology, University Children's Hospital Muenster, Münster, Germany

21 Institute of Oncology, Radiology and Nuclear Medicine, Dmitry Rogachev National Research Center of Pediatric Hematology, Oncology and Immunology, 1 Samory Mashela str, 117997 Moscow, Russia 